\title{
Re-solved. Iterating design solutions by understanding failure
}

\author{
Peter McPherson, Annabel Pretty \\ Unitec Institute of Technology, New Zealand \\ School of Architecture \\ pmcpherson@unitec.ac.nz | apretty@unitec.ac.nz
}

\begin{abstract}
Design is considered one of the most important parts of an architectural education. Much emphasis is placed upon the Design Studio within a School of Architecture, yet in the traditional tutor/student model how much opportunity is there for the student to understand the process of designing when emulation forms the heart of the learning? This paper reflects upon a series of large scale fabrication projects offered to students from 20I2-20I4 in Christchurch, New Zealand, under the umbrella of FESTA. These projects challenged the students to confront a series of 'firsts'; to work collaboratively, to present themselves professionally, to navigate regulatory bodies, to engage with a client, and to realise a project at full, one to one, scale.

These projects tend to exist without a specific precedent for students to draw upon, as would be usual when designing one of any number a normal building typology. This forces students into a space of discovery, one where a design can change for any multitude of reasons. Students are moved from the usual Design Studio experience of problem solving to one where the situation is uncertain and problematic, to a space of problem setting.
\end{abstract}

Keywords: design process, iterative, fabrication, prototype, technology.

\section{To cite this article:}

McPherson, P., Pretty, A. (2017). Re-solved: iterating design solutions by understanding failure. The Journal of Public Space, 2(3), Special Issue, 167-176, DOI: I0.5204/jps.v2i3.I 25

This article has been peer-reviewed and accepted for publication in The Journal of Public Space. Please see the Editorial Policies under the 'About' section of the journal website for further information.

This work is licensed under a Creative Commons Attribution - Non Commercial 4.0 International License https://creativecommons.org/licenses/by-nc/4.0/ 
The majority of a student's time in a school of architecture will be spent toiling away in the design studio. Given the vast amounts of time spent on this part of an architectural education it would be easy to surmise that designing is the most important skill that a student can learn. The importance placed on design would suggest that we believe that the act of designing can be taught, that when a student leaves his or her education they will be a better designer than when they entered'.

A key part of an architectural education in the usual design studio environment is one of emulationPIF $F^{2}$,. Students are required to research precedents of a typology or topic and extrapolate a response to a specific design brief. The design studio is headed by a studio master to whom students will present a series of responses for individualised critique and subsequent advancement. This back and forth will occur until such time as a level of competency is determined as achieved by the student or until the project deadline arrives. Other than the reliance on the feedback of the studio master or learning from precedent studies there is little to guide the student in advancing their project. The learning could be considered passive with little active engagement from the student required in the process. Students are, as Donald Schön puts it, problem solving rather than problem setting and as such, have little opportunity to understand the process of designing.

"From the perspective of Technical Rationality, professional practice is a process of problem solving. Problems of choice or decision are solved through the selection, from available means, of the one best suited to established ends. But with this emphasis on problem solving, we ignore problem setting, the process by which we define the decision to be made, the ends to be achieved, the mains which may be chosen. In real-world practice, problems do not present themselves to the practitioner as givens. They must be constructed from the materials of problematic situations which are puzzling, troubling and uncertain."

Donald A. Schön, The Reflective Practitioner: How Professionals Think in Action (New York: Basic Books, 1983), 5I-52.

It is curious that architectural studio teaching in its usual form tends to limit students to seek and apply solutions to a known problem of an architectural typology. We know that students will tend to produce the obvious $\mathrm{P}^{3} \mathrm{~F}^{3} \mathrm{P}$ and this will reduce their capacity to understand at a meaningful level what is being asked from them. There is another approach to the design studio, one that places design-led research at the front of an architectural question to engage students in a way that empowers them in the process of not only solving problems but also in the setting of design problems. This can be facilitated by the 'live project'.

Ruth Morrow discusses the relationship between Design Studio projects and Live Projects, in particular, that Live Projects may be set up to serve a different role from Design Studio

\footnotetext{
' Michael Brawne, "Can We Describe How We Design?" in, Educating Architects: How tomorrow's practitioners will learn today, ed. Neil Spiller \& Nic Clear (New York, New York: Thames \& Hudson, 20I4), 72.

2 Mark Morris, "School of Thought," in Educating Architects: How tomorrow's practitioners will learn today, ed. Neil Spiller and Nic Clear (New York, New York: Thames \& Hudson, 20 I4), 17 I.

${ }^{3}$ Professor Sir Peter Cook, "Timing is everything... or is it?" in, Educating Architects: How tomorrow's practitioners will learn today, ed. Neil Spiller and Nic Clear (New York, New York: Thames \& Hudson, 20I4), 23.
}

I 68 | The Journal of Public Space, 2(3), 2017 | Special Issue | ISSN 2206-9658

(C) Queensland University of Technology 
projects. ${ }^{4}$ We agree that Live Projects introduce students to a range of alternative skills, particularly around collaborative agency. And by situating the following case studies within a community situation, we see how the role of people in the design process, the client and end user, contribute to challenging any presumptions students might have about their projects. In these projects students are taken outside of the usual design studio environment in order to contribute to the reinstatement of an urban environment in the recently devastated Christchurch CBD. In creating objects and places for people to engage students encounter problems of real significance. They are put into the position of 'problem setting', into a process of iterating design solutions or, another way, of re-solving architectural problems.

\section{FESTA Large Scale Fabrication Studios}

The large scale fabrication studios undertaken as part of the Festival of Transitional Architecture (FESTA) presented an abstract problem to students to solve, namely to realise temporary architectural projects at a city scale for public consumption for a single night. The students were drawn from architecture and design departments at the University of Auckland (SoAP), Christchurch Polytechnic (CPIT), Auckland University of Technology (AUT), Victoria University of Wellington (VUW) and Unitec.

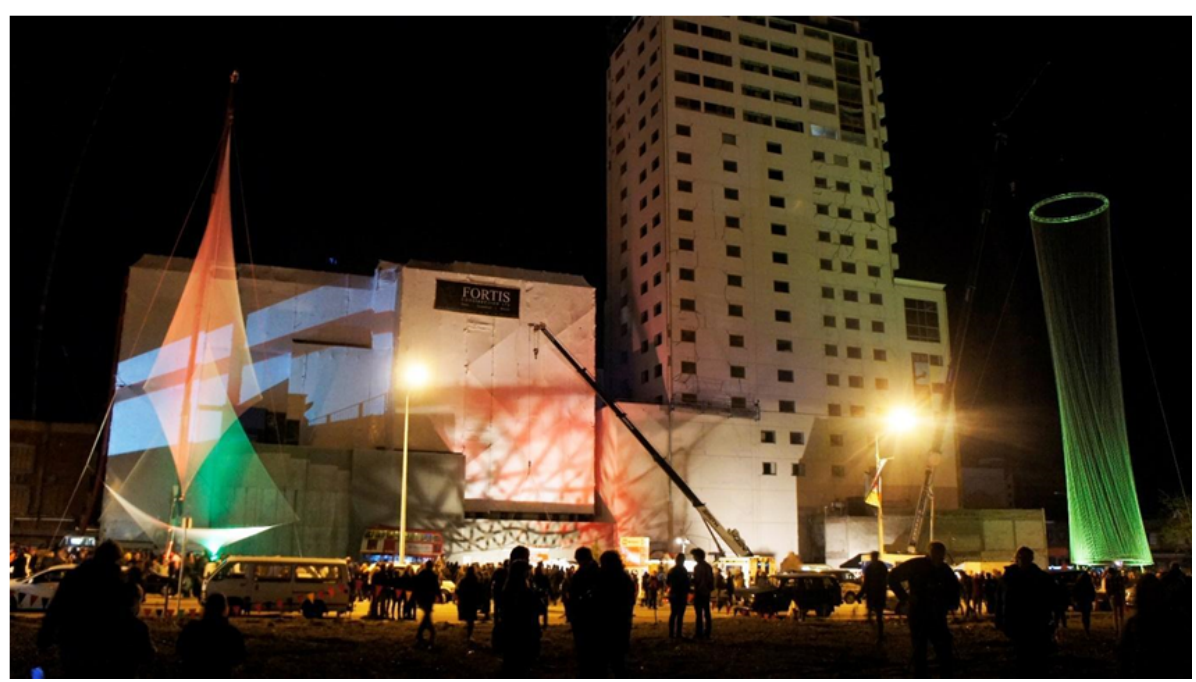

Figure I. Peter McPherson, Archrobatics, Team Tensile, Altitude, LuxCity, 2012.

In each of the programmes $(2012,2013$ and 2014) the installations required interaction with the public as well as engagement with a local client. In every case projects started out with a zero-dollar budget. Many 'firsts' occur in this project; the first time students are required to work collaboratively, the first time students present or market themselves externally, the first time students negotiate council regulations, the first time students engage with a client, the first time students realise a project at full scale and, the first time end users will pass judgment on their work.

\footnotetext{
${ }^{4}$ Ruth Morrow, "Foreword. Live Project Love: building a framework for Live Projects" in, Architecture Live Projects: Pedagogy into Practice, ed. Harriet Harriss and Lynnette Widder (New York, New York: Routledge, 2014), xvii-xxiii.
} 
These 'firsts' are of course generalisations but serve to contextualise where the project sits within a student's education and the multitude of new challenges that are faced with such a task. They also highlight where the regular studio experience, which focusses on the individual, might exclude exposure to a number of necessary skills required by students for their professional careers $\mathrm{P}^{5} \mathrm{~F}^{5} \mathrm{P}$. Additionally, in having very little precedent for the outcome there is an emphasis placed on discovery, on the iterative nature of the design process as new challenges are faced and solutions pursued.

The focus of this paper is on the programme offered in 2012, the first iteration of the projects with FESTA. As the FESTA event evolved over three years so too did the framework within which the projects sit, largely driven by stricter council controls. These first projects then offer greater diversity to choose from when analysing the student approach.

Small teams of students, 4-6 in number, initially presented preliminary research and exploration to a jury panel. Students were encouraged from the outset to make things and explore the physical properties of light and materials. This led to a number of highly inventive ideas at a conceptual level with a great capacity to be scaled up to a city sized realisable structure. Through working with a variety of media and scales students are able to better understand the full consequences of their design decisions. What begins as a small jelly cube with a light inside (and perhaps questionable architectural value) might come to be an entire interactive field of light for people to walk through.
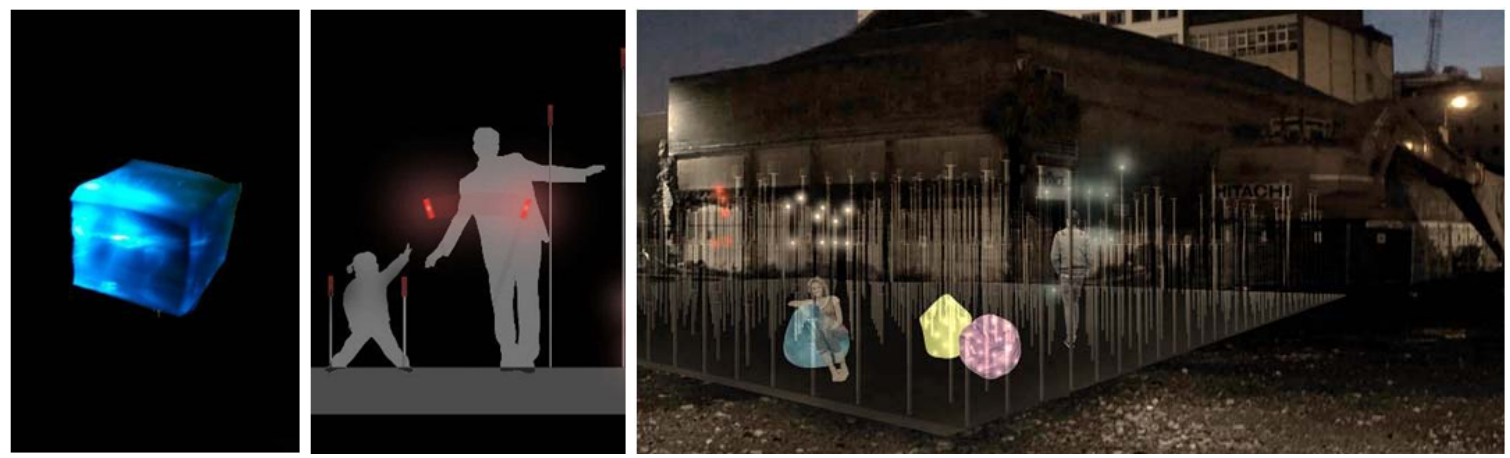

Figure 2. The Wobblers, Concept Design, LuxCity, 2012.

The projects undertaken in Christchurch required economy of means. The projects had to be transported from Auckland to Christchurch (ideally within the standard airline luggage limits), be erected within a day for a single night event and then removed without trace of waste at the end of the night. This moved students into the direction to explore the qualities of light and lightness, both the medium of light and materials with physical lightweight characteristics.

The following case studies examine some of these issues.

\footnotetext{
${ }^{5}$ Mark Burry, "Making a difference: Embedding academic research in practice" in, Educating Architects: How tomorrow's practitioners will learn today, ed. Neil Spiller \& Nic Clear (New York, New York: Thames \& Hudson, 2014), 327.
} 


\section{Silhouette Carnival}

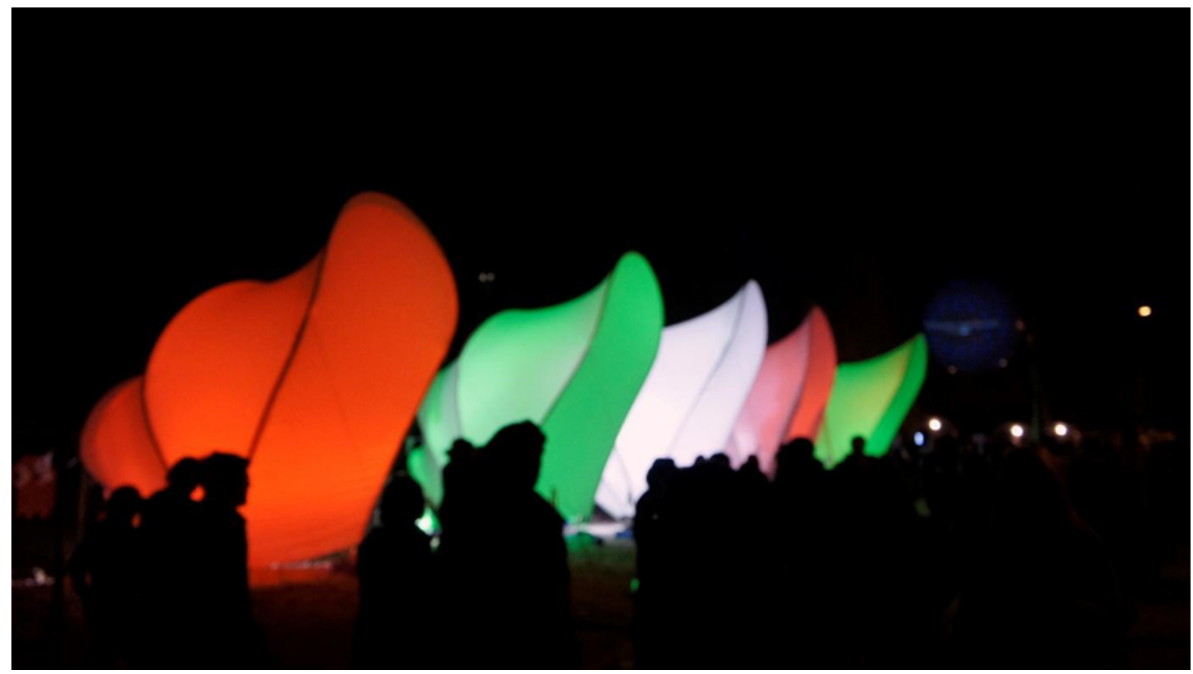

Figure 3. Peter McPherson, Silhouette Carnival, LuxCity, 2012.

The initial concept for this project was established by a group of Chinese International students based on their understanding of traditional Chinese Shadow Theatre. The project used the notion of projection of a light source onto a body so that the silhouette could be viewed on a translucent surface. This meant that the origin of the light could be small but had the challenge to construct a suitable surface onto which the silhouette could be viewed.

The initial group were combined with a group of students whose original project sought to create free-standing objects from construction materials, drawn from the concept of the Terrain Vague. The two teams were merged due to complimentary skills and also as each project offered possibilities for exploration to the other.
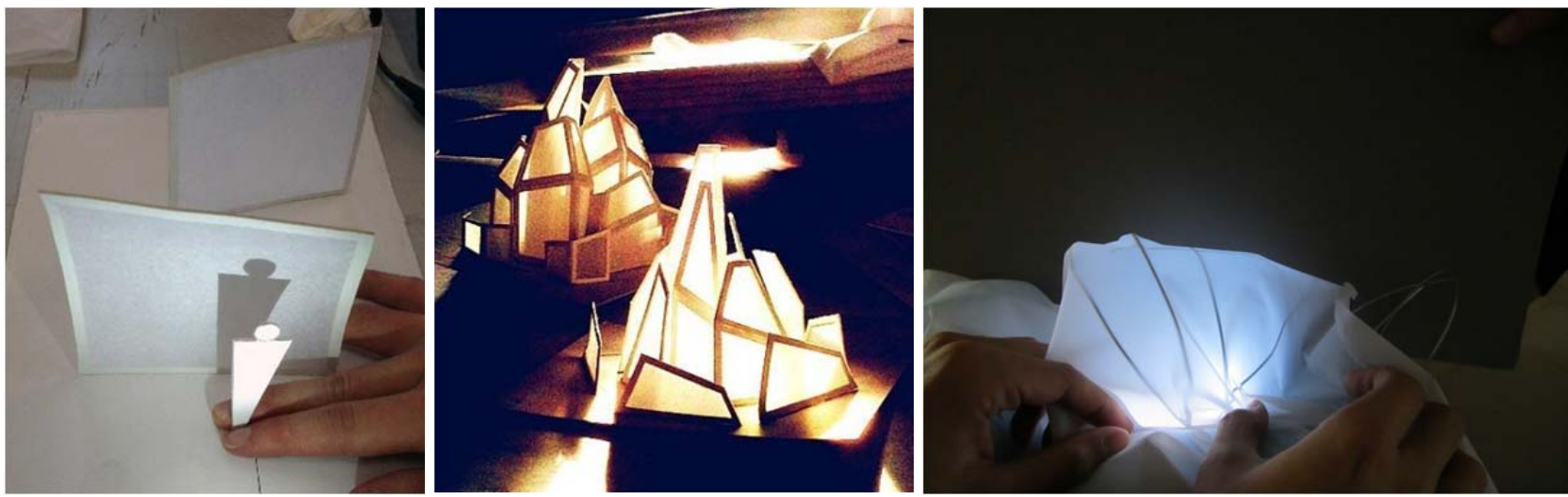

Figure 4. Silhouette Carnival, Concept Design and Development, LuxCity, 2012.

With the lighting aspect of the project generally understood, the combined team set to explore methods for constructing free-standing projection screens. This necessitated engaging with issues of construction at an early stage to test how materials would react in an external environment. The initial layout for a concentric arrangement of planar elements began to give way to more three-dimensional shell type structures that an 'actor' 
could inhabit. This began to work with the associated client for the project, the Free Theatre Christchurch who began to programme activities that would engage with the built structure. New challenges were added by where structures could be picked up and moved yet still remain free-standing when not in use by the actors.

Another layer of detailed design exploration was therefore required to examine how the structure would connect to the ground. The project site shifted from sealed to unsealed surfaces several times as negotiations regarding the overall project boundaries ensued. A solution that could meet either condition was required.

As the design developed the footing connection began to inform how the overall shell structure could be formed, with curved members springing from a single point. With a basic shape becoming finalised, further criteria for the material investigations for the shell covering were established. The group established the parameters by which the material needed to perform; the ability to receive and transmit a shadow, to warp and twist to a form, to absorb and allow wind to pass through and, to give some element of rain protection. Experiments again were undertaken initially at a scale model level and then at half and full scale realisations.

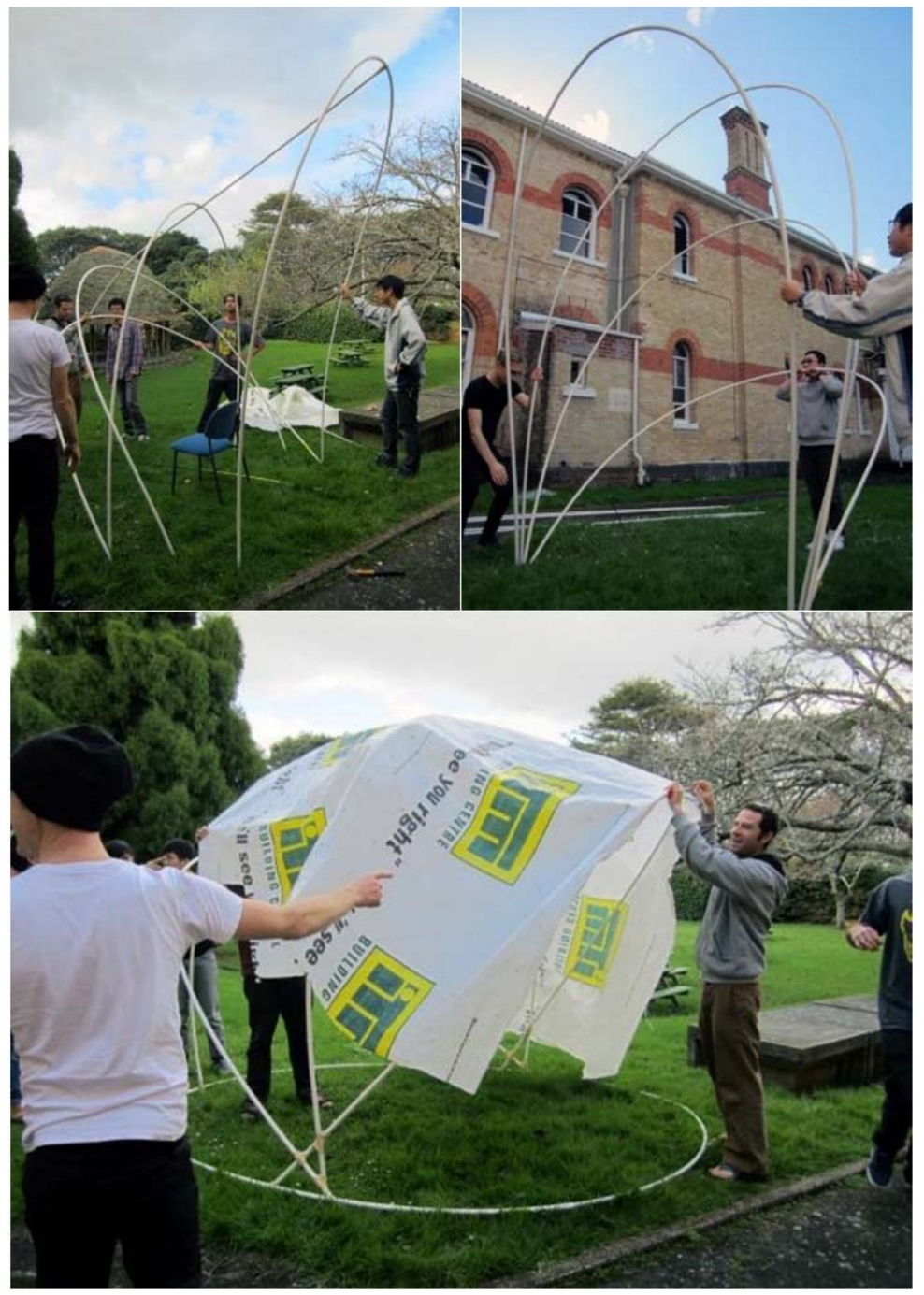

Figure 5. Silhouette Carnival, Concept Design and Development, LuxCity, 2012. 
Throughout the process students realised the need to gain new skills for construction as well as learning how materials and means of fabrication will affect design decisions. Some learned to sew while others to weld and all of them to tie knots! The success of this project could be measured at many levels; the integration of two design concepts and cultural backgrounds provided a fertile environment for growth and learning from oneanother; the ability for the design to respond to a variety of physical conditions including a last minute change of site; and the ability for the project to remain successful at a social level by enabling public engagement when in the final moments it became apparent that the client wouldn't be able to partake in the event.

Reflecting on the work carried out by this group of students we clearly see them setting themselves problems to be re-solved, a critical aspect of learning to understand the design process. Alongside this the number and variety of solutions presented emphasise how iterating enabled the students to solve the problems they set themselves in their realisation of a large scale architectural installation.
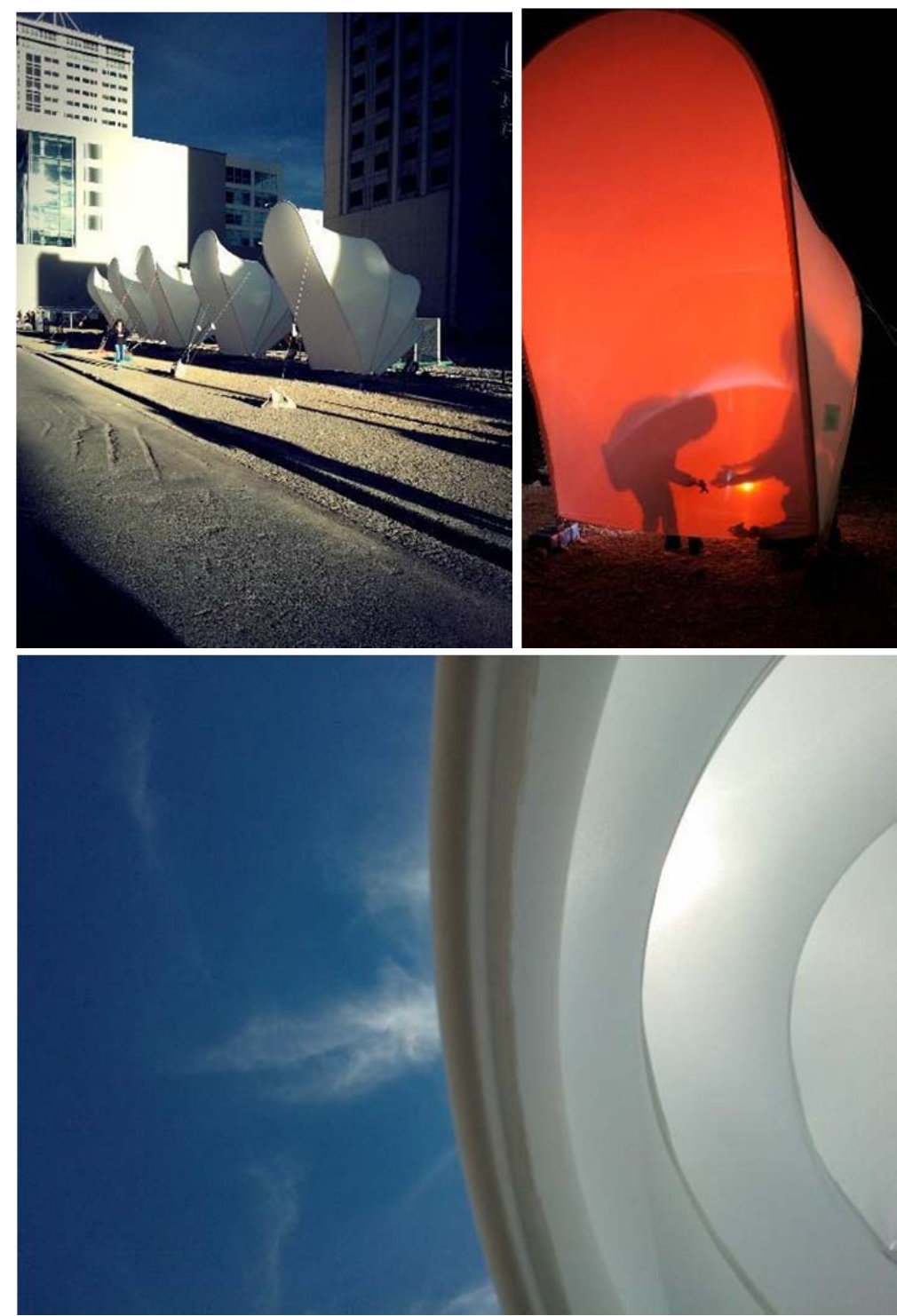

Figure 6. Peter McPherson, Silhouette Carnival, LuxCity, 2012. 


\section{Archrobatics}

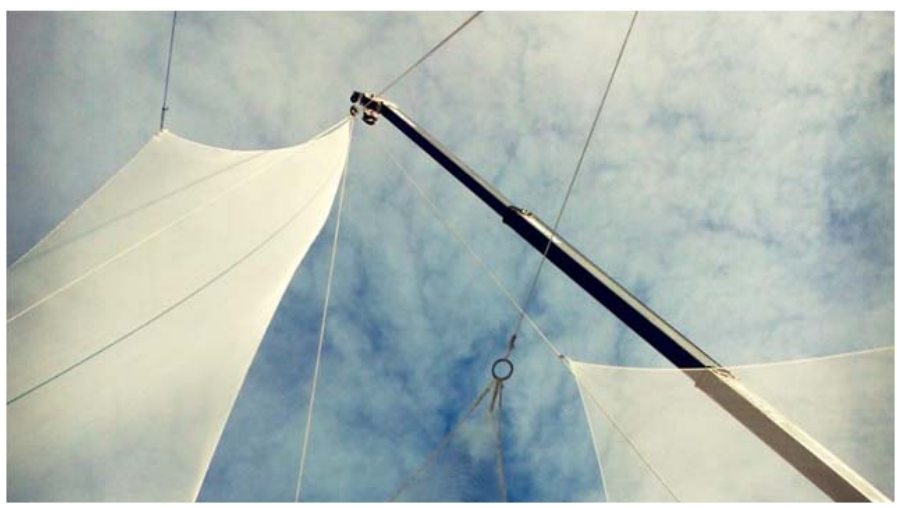

Figure 7. Peter McPherson, Archrobatics, LuxCity, 2012.

The team Archrobatics started life as Spherical Sounds, a scheme utilising glowing spheres to illustrate the call of a Tui, a native New Zealand bird. The intent was to create a structure suspended overhead, establishing an environment below for the public to engage with. This project underwent the most radical of formal transformations of all the groups and finally resulted in a beautiful elegant structure.

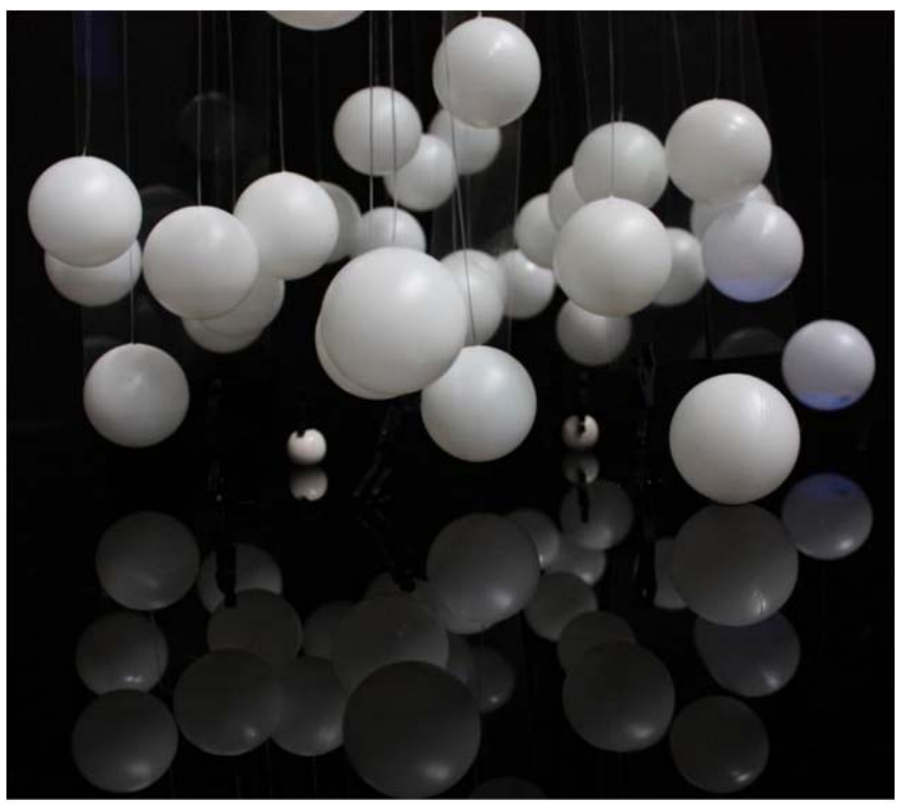

Figure 8. Archrobatics, Design Concept, LuxCity, 2012.

In working through variations of their initial design proposal the idea that appeared achievable at a small scale was becoming unwieldy at full size. In setting about resolving the design challenges presented by the initial scheme students concluded that it was proving too expensive and unreliable to construct, not to mention posing physical danger, and the group came to the conclusion that a change in direction was necessary.

With a focus on achievability and simplicity the group looked at a single point of vertical suspension from what would be a crane hook, 30 plus meters above the ground. The pyramid type structure that was emerging was used to suspend the spheres from the initial 
concept within. At this time a rigid structure with steel cables was imagined with the spheres being the light emitting object. As continued exploration into materials, including the spheres and alternatives were undertaken, a decision to omit the spheres altogether and focus on the shapes that could be formed by the structure itself was made. As considerations regarding site and flexibility were also included greater levels of flexibility were considered and explored for the overall structure eventually resulting in rope forming the guiding members. In testing materials criteria were established by the group where wind loading would be the dominant factor given the height of the structure, along with lightness, the ability to accept light cast upon it from LED light sources and the ability to flex and hold a shape under tension. The group eventually settled upon agricultural bird netting.

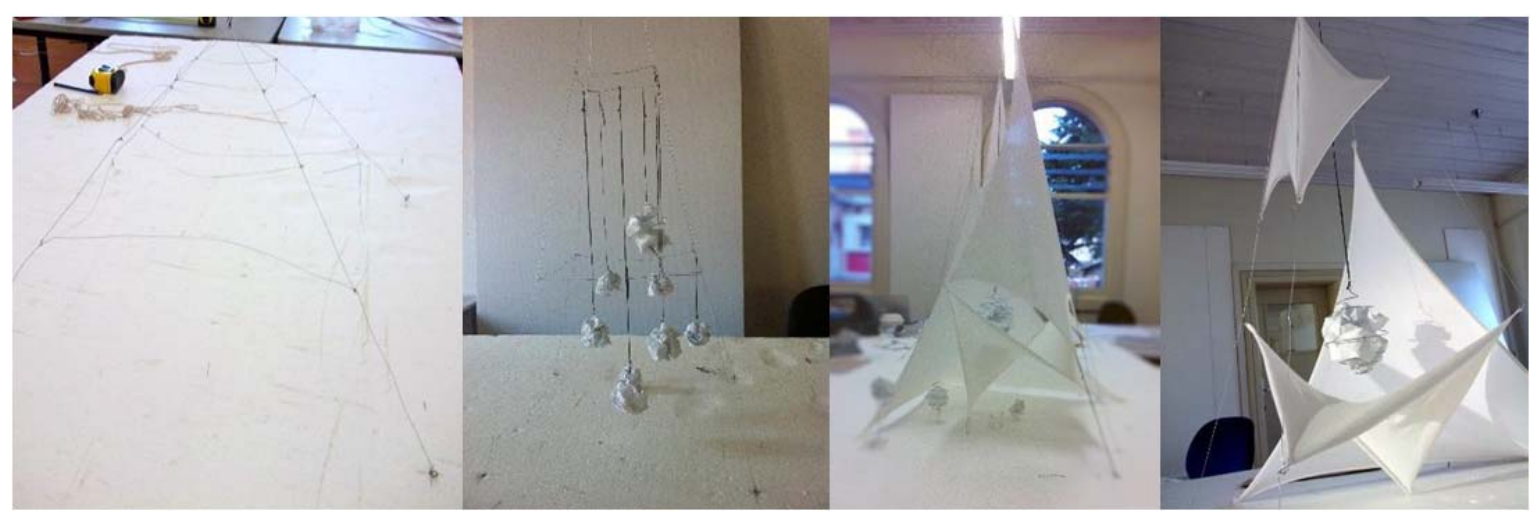

Figure 9. Archrobatics, Developed Design Concepts, LuxCity, 2012.

Grounding the structure was another design challenge, met mostly through the use of deadman weights but also through the filling of empty sacks filled with rubble from the site itself. Through testing of the construction technique using rope, netting and lights and a variety of scales and settings the group were confident that they could quickly erect and adjust their full scale scheme onsite.

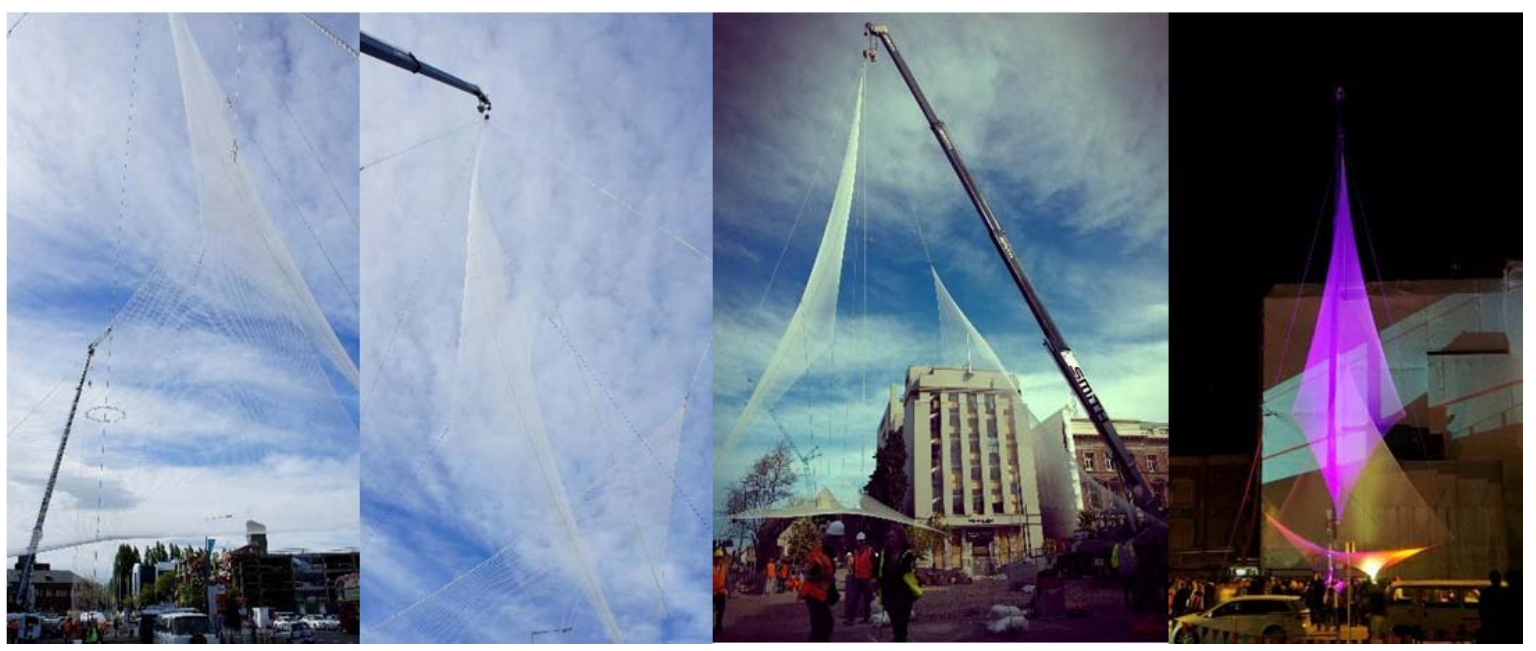

Figure 10. Peter McPherson, Archrobatics, LuxCity, 2012. 
The particular success of this project lay in students' ability to identify there being an issue with the initial design proposal. What might be considered a failure provided the basis for the group to better understand their constraints, establish priorities and reset their design problem, demonstrating their learning from earlier setbacks. Learning from failure is an important aspect of design and failure can be considered a success if students are able to demonstrate learning from it. ${ }^{6}$ Failure additionally highlights to students that design solutions can change for any number of reasons, again encouraging them to iterate in their design thinking. In being able to re-establish and re-solve the design problem, goals and objectives, the group was able to achieve one of the most successful outcomes of the evening. All material was transported on the aeroplane, the project was erected in a short period of time with site specific adjustments to the overall shape incorporated and de-installation of the project took moments with zero waste left behind, save for what was already found onsite initially. The project itself had an ephemeral quality to it during the daytime and as day turned to night the beauty of the three hyperbolic forms came to life on a city scale.

\section{Conclusion}

The two case studies presented here are examples of live, situated and community based projects that highlight to students two key components of the design process; iteration and failure. In exposing students to these types of projects, failure becomes a core part of the learning. Failure is critical in the resetting of the design problem and hence, in empowering students to engage with and develop their own design problems. In understanding failure in the context of their own parameters the reasons to alter a design, to iterate, become more tangible to students than in the usual design studio environment. In better understanding the reasons for altering a design alongside the setting of their own design problem, ${ }^{7}$ students become more engaged and aware of their thinking and process. This is in contrast to the traditional student and mentor design studio relationship where design is guided and the student can remain removed from the process of understanding the problem. Students are instead able to challenge what an architectural outcome might be for a given situation. A key component to establish understanding of the architectural problem is the production of an architectural object, to be used by others. This moves students outside of the usual teacher-student learning relationship and the realisation of the architectural object becomes ${ }^{8}$ linked to the design process itself, the distinction between design and process blurs ${ }^{9}$ with the two becoming linked in the student's mind.

Through an open brief that demands a real architectural outcome to be placed within a community we find a model of design studio that emphasises the adoption of critical skills required to be a successful designer. Specifically, the necessity to iterate a design problem, to fail and to understand those failures within set design problems of one's own making. These projects equip students with an understanding how to set problems and, how to resolve them.

\footnotetext{
${ }^{6}$ Harriet Harriss, "Co-Authoring a Live Project Manifesto," in Harriss and Widder, Architecture Live Projects, 45.

${ }^{7}$ Schön, The Reflective Practitioner, 5 I-52.

${ }^{8}$ Donald A. Schön, The Reflective Practitioner: How Professionals Think in Action (New York: Basic Books, 1983), $51-52$.

9 James Benedict Brown, “Learning Theories for Live Projects," in Harriss and Widder, Architecture Live Projects, 22.
}

I 76 | The Journal of Public Space, 2(3), 2017 | Special Issue | ISSN 2206-9658

(C) Queensland University of Technology 